\title{
A INTERLOCUÇÃO ENTRE PARES: CONTRIBUIÇÓES PARA A REFLEXÃO DA PRÁTICA PEDAGÓGICA DO PROFESSOR-FORMADOR
}

\author{
Ademar Antonio Lauxen ${ }^{1}$ \\ José Claudio Del Pino ${ }^{2}$
}

\begin{abstract}
Resumo: A análise das concepçóes epistemológicas e educacionais de ensinar e aprender de professores-formadores pode apontar a racionalidade que fundamenta a atuação desses educadores em cursos de graduação, especialmente nas licenciaturas. A investigação visou a perceber quanto um grupo de professores e professoras atuantes em um curso de Licenciatura em Química de uma instituição de ensino superior têm ampliado seus saberes docentes a partir de um espaço/tempo institucional existente e em que medida isso tem implicado em mudanças no fazer pedagógico de cada um. O presente texto é resultado de um estudo, de caráter qualitativo, situado no contexto da investigaçáo-ação. A pesquisa aponta que a formaçáo continuada e os processos reflexivos que dessa decorrem, os momentos de socialização, a análise e a reflexão das práticas pedagógicas com seus pares e a constituição de espaços/tempos intrainstitucionais são importantes para promover novos estágios de compreensão aos sujeitos-atores do processo educativo, contribuindo para a problematização de saberes e reconfiguração da ação.
\end{abstract}

Palavras-chave: Aprender. Ensinar. Formação docente. Saber-docente.

\section{INTERLOCUTION BETWEEN PEERS: CONSTITUTIONS TO THE REFLECTION OF THE TEACHER-TRAINER PEDAGOGICAL PRACTICE}

\begin{abstract}
The epistemological and educational conceptions analysis of teaching and learning of teachers-educator could indicate the rationality which substantiates the performance of these teachers in graduation courses, especially in degrees. The research aimed to realize how much a
\end{abstract}

1 Doutor em Educação em Ciências (UFRGS); Mestre em Educação nas Ciências (Unijuí); Professor da Universidade de Passo Fundo; Coordenador da Área de Química-UPF.

2 Professor do PPG Educação em Ciências: Química da Vida e Saúde. Pós-doutor pela Universidade de Aveiro - Portugal. Doutor em Engenharia de Biomassa - UFRGS. Mestre em Ciências Biológicas - Bioquímica - UFRGS. 
group of active teachers in a degree course in chemistry of a higher education institution have been expanding their teaching knowledge from a existing institutional space/time and how much of it has been resulting in changes in each one's teaching way. This text is the result of a study, of qualitative character, situated in the context of investigation-action. The research highlights that continued education and the reflective processes that accrue from it, the socialization moments, analysis and reflection of pedagogical practices with their pairs, and the formation of intra-institutional spaces/ times are important to promote new understanding stages to subjects-actors of the educational process, contributing to the questioning of knowledge and reconfiguration of action.

Keywords: To learn. To teach. Teacher training. Teaching knowledges.

\section{Introduçáo}

Há vários desafios impostos à educação brasileira, tornando necessária a reflexão acerca de açóes que possam contribuir para a melhoria de qualidade. Cury (2014) aponta que a qualidade desejada depende de aspectos relacionados a questóes de cunho pedagógico, da formação inicial e continuada dos docentes, dos planos de carreiras e da remuneração do profissional, que exige salários mais atrativos. Barbosa (2014) sinaliza que um conjunto de fatores tem ocasionado uma baixa procura pelos cursos de licenciatura, o que tem levado à redução no número de professores nas diferentes redes de ensino. Machado (2007) destaca a natural necessidade da formação continuada dos professores, aspecto capaz, dentre outros, de contribuir para a qualidade na educação.

Diferentes estudos (LIBÂNEO; PIMENTA, 1999; LIMA et al., 2007; LIBÂNEO, 2015; VARGAS; PEIXOTO, 2019, dentre outros) consideram que a formação dos educadores é pauta importante quando a temática é a qualidade da educação. Parece ser consenso dos diferentes estudos quanto a necessidade da inserção no debate a questão da formação de professores, tanto inicial, quanto continuada, para qualificar o processo educacional. Porém, o que, ainda, não parece ser consenso é a forma, ou quais as melhores metodologias e os mais adequados instrumentos para que se possa atingir os objetivos desejados nesse aspecto.

Existem políticas públicas que visam contribuir com o aumento na qualidade da formação dos educadores, dentre essas podemos destacar o Pibid (Programa Institucional de Bolsa de Iniciação à Docência), que é uma iniciativa da Capes ${ }^{3}$ em parceria com as diversas universidades brasileiras para o aperfeiçoamento e a valorização da formação de professores para a educação básica. Porém, essas iniciativas, isoladamente, não garantem a qualidade, caso não haja uma proposta curricular que sustente a formaçáo do educador no decorrer dos anos de graduaçáo.

As propostas curriculares dos cursos de graduação nascem de consensos e negociaçôes entre os educadores que constituem os colegiados dos referidos cursos. Sabe-se que, na construção do currículo de um curso de graduação e de sua proposta

3 Coordenação de Aperfeiçoamento de Pessoal de Nível Superior (Capes), fundação do Ministério da Educação (MEC). 
pedagógica, deve-se atender aos parâmetros legais emanados da LDBEN (Lei de Diretrizes e Bases da Educaçáo Nacional). Em se tratando de curso de licenciatura, atentar para as Diretrizes Curriculares Nacionais específicas para formação de professores, para as Diretrizes Nacionais de cada área do conhecimento, bem como para o Plano Nacional de Educaçáo. No entanto, dependendo das concepçóes e compreensôes pedagógicas e técnicas do conjunto de professores-formadores que pensam e elaboram o currículo do curso de graduação, novas ou velhas tendências e compreensões poderão estar presentes, as quais irão contribuir na constituição do modus do futuro educador que será formado.

Esses grupos são dinâmicos e, diante dessa característica, faz-se necessária a constante revisita às propostas pedagógicas, para que aqueles que no curso passem a atuar tenham presente os princípios norteadores para a formação do egresso. Além disso, a prática docente é revestida de tamanha complexidade, que nem sempre é compreendida com a clareza necessária pelos educadores. Em muitos dos professoresformadores está presente uma visão simplista do ato de ensinar que se constituiu de forma tácita ao longo de sua formação e, por isso, necessita ser problematizada para que não seja reproduzida sem reflexão e venha a influenciar na formação do futuro educador. Maldaner (2013, p. 54) aponta que "os professores manifestavam, em muitas ocasióes, as suas crenças nas mesmas bases epistemológicas sobre as quais 'edificaram' a sua representação de conhecimento químico e profissional". E, conclui: "Tudo isso poderia ser traduzido como concepçóes (tácita) de currículo que os professores adotam" (MALDANER, 2013, p. 54, grifo do autor). "Outro problema nesses cursos é o fato de que as teorias curriculares tradicionais são ainda dominantes, especialmente nos professores das disciplinas de conteúdo específico" (GALIAZZI, 2011, p. 140). Portanto, compreensôes sobre o processo do ensinar e do aprender que os professores-formadores construíram ao longo de sua formação vão impregnar as propostas dos cursos em que atuam.

Assim, este texto busca discutir o que pensam, sobre o aprender, o ensinar, a açáo docente e o seu próprio processo de formação, o grupo de professoresformadores, atuantes em um curso de graduação voltado para a formação de professores. $\mathrm{O}$ estudo em questáo analisa o resultado decorrente das entrevistas realizadas com dez professores-formadores. Essas entrevistas fazem parte de um conjunto de açóes para a coleta de dados que foram utilizados na investigação de doutoramento.

Os entrevistados integram, também, o Núcleo de Educação Química, espaço/tempo intrainstitucional constituído para a formação continuada desses docentes, visando aos debates e estudos sobre os processos do ensinar e aprender, possibilitando a constante ressignificação da prática pedagógica de cada um dos envolvidos nesse contexto.

Desse modo, entende-se como importante compreender o que pensam esses professores-formadores acerca de aspectos da educação e da formação docente, especialmente se desejamos que a formação para a docência tenha melhor qualidade e possa contemplar os desafios da contemporaneidade. 
Sendo assim, o principal objetivo desse trabalho foi compreender o processo de formação continuada dos professores-formadores de um curso de Química Licenciatura, e elucidar como esses mobilizam e articulam os seus saberes, no diálogo com os seus pares, tendo em vista que, muitas vezes, os saberes para a docência não foram desenvolvidos e aprendidos na sua formação inicial. Ao mesmo tempo, desejou-se investigar como esse processo de construção e reconstrução de saberes contribui na formação do futuro educador da educação básica. Visou, ainda, perceber quanto o Núcleo de Educação Química, espaço/tempo intrainstitucional, constituído para ajudar na formação continuada do professor-formador, tem contribuído para a produçáo e o desenvolvimento de práticas pedagógicas mais refletidas, com a construçáo de processos de ensino e aprendizagem mais comprometidos com o desenvolvimento intelectual dos educandos.

\section{Aspectos metodológicos da pesquisa}

A presente pesquisa teve uma abordagem qualitativa na perspectiva da investigação-ação ou da pesquisa em ação, pois foi além da simples constatação e configuração de um problema, visou estabelecer um sentido de horizontalidade no processo do conhecimento e ação entre pesquisador e realidade, pesquisador e pesquisado (BOGDAN; BIKLEN, 2010; LÜDKE; ANDRÉ, 2013). Corroboram Lüdke e André (2013) ao afirmarem que esse tipo de pesquisa visa à descoberta do "onde" o conhecimento se faz e se refaz constantemente, fazendo emergir novos elementos no decorrer do processo.

Os dados apresentados são decorrentes de uma entrevista realizada com dez professores-formadores, atuantes em um curso de Licenciatura em Química e integrantes do Núcleo de Educação Química (NEQ). O NEQ é composto por professores que integram a área de Química, tendo esses carga horária semanal destinada para essa finalidade. Todos foram convidados a participar da pesquisa, porém dois declinaram do convite, sendo que uma professora justificou por estar em licença para doutoramento. A pesquisa se insere, também, na perspectiva de estudo de caso ao caracterizar-se pela descoberta, pela interpretação contextual, pela multiplicidade dimensional de certo cotidiano, pela recorrência a diversas formas de informaçáo. Segundo Yin (2001), o estudo de caso torna-se útil quando o que se apresenta é vasto e complexo e náo pode ser analisado fora do espaço em que ocorre.

A entrevista foi realizada de forma individual, com a participaçáo de cada um dos professores-formadores e o entrevistador, gravadas em áudio, em sala sem a interferência externa, com questôes semiestruturadas, sendo, posteriormente, transcritas.

No presente texto, analisam-se as manifestaçóes primeiras, os recortes das falas dos entrevistados, aquelas apresentadas a partir das questôes semiestruturadas, em que se busca perceber o que pensam esses professores-formadores sobre o que é ensinar, aprender, quais são os saberes docentes e quais suas preocupaçóes com a sua formação. Os dados foram analisados com base nos argumentos de Moraes e Galiazzi (2016) sob a ótica da Análise Textual Discursiva: “[...] processo de 
desconstruçáo, seguido de construção, de um conjunto de materiais linguísticos e discursivos, produzindo-se a partir disso novos entendimentos sobre os fenômenos e discursos investigados" (MORAES; GALIAZZI, 2016, p. 134). Os autores também apontam que "Fazer análises qualitativas de materiais textuais implica assumir interpretaçóes de enunciados dos discursos, a partir dos quais os textos são produzidos, tendo consciência de que isso sempre envolve a própria subjetividade" (MORAES; GALIAZZI, 2016, p. 135).

Para preservar a identidade dos participantes da pesquisa e identificá-los ao longo do texto em suas diferentes manifestaçôes, atribuíram-se nomes fictícios, a partir de nomes de personagem da História das Ciências da Natureza. Todos os participantes preencheram e assinaram o Termo de Consentimento Livre e Esclarecido (TCLE), autorizando o uso dos dados.

A seguir, o Quadro 1 apresenta a formação em nível de graduação e pósgraduação dos entrevistados, bem como as disciplinas de atuação desses.

Quadro 1: Formação e atuação docente dos entrevistados

\begin{tabular}{|c|c|c|c|}
\hline & & & $\mathbf{N}^{\circ}$ de entrevistados \\
\hline \multirow{6}{*}{ 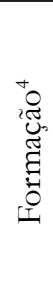 } & \multirow{3}{*}{ Graduação } & Licenciatura & 5 \\
\hline & & Bacharelado-industrial / Licenciatura & 4 \\
\hline & & Engenharia Química & 1 \\
\hline & \multirow{3}{*}{ Pós-graduação } & Doutorado & 2 \\
\hline & & Mestrado & 7 \\
\hline & & Especialização & 1 \\
\hline \multirow{7}{*}{ 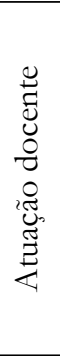 } & \multirow{7}{*}{ Disciplinas } & Química Orgânica & 1 \\
\hline & & Química Inorgânica & 2 \\
\hline & & Química Geral & 2 \\
\hline & & Pedagógicas e Estágios & 2 \\
\hline & & Tecnológicas & 1 \\
\hline & & Química Analítica & 1 \\
\hline & & Grupos práticos de Química Orgânica & 1 \\
\hline
\end{tabular}

Fonte: Elaborado pelos autores

\section{Construindo significados a partir dos elementos de pesquisa}

Neste trabalho serão analisadas cinco questões que foram apresentadas aos entrevistados. A escolha se deve ao entendimento de que essas estão relacionadas entre si e corroboram no sentido de sinalizar quais saberes são mobilizados, articulados e produzidos pelos professores-formadores na construçáo de processos

4 O professor com especialização realizava mestrado no período da pesquisa; dos sete professores com mestrado, cinco se encontravam em processo de doutoramento no período da pesquisa. 
de ensino e aprendizagem. As questóes versaram sobre o entendimento/concepçáo de cada um sobre o "ensinar" e o "aprender", e em relaçáo ao processo de formação continuada, considerando a participação em eventos, a leitura de periódicos e livros, e a contribuiçáo dessas práticas para aspectos ligados ao aperfeiçoamento profissional e pessoal, e suas açôes como professor(a). Ainda, avalia-se a existência (o papel; as açóes; as atividades) do Núcleo de Educação Química (NEQ) para a constituição como educador(a) e, se as discussôes e estudos realizados no NEQ contribuíram/contribuem para a melhoria da ação pedagógica de cada um.

O Núcleo de Educação Química (NEQ) foi instituído em 2003, por iniciativa do coletivo de educadores ligados a área de Química, tendo como objetivo principal de ser um espaço/tempo para estudos, discussóes, pesquisa e articulação de estudantes e professores acerca do processo de ensinar e aprender em Química. Ao longo de sua existência, o NEQ tem se constituído como espaço/tempo que oportuniza aos seus integrantes a ressignificação da sua prática pedagógica, bem como possibilita que esses construam materiais didático-instrucionais e pensem na constituição de ambientes de aprendizagens que possam ser significativos para o ensinar e aprender. Esse espaço/tempo visa estabelecer um processo coletivo de constante ação-reflexão-ação, permitindo estabelecer a interface entre ensino, pesquisa e extensáo constituindo os professores-formadores, também, como pesquisadores no campo do ensino e da aprendizagem em educação química.

Assim, com esse estudo aspirou-se a reconhecer quais saberes o professorformador expressa sobre o ensinar e o aprender, pois julga-se essa concepção como fundamental, estando aliada aos processos de formação continuada que podem ajudar a perceber como cada um organiza e gerencia essa formaçáo com vistas a qualificar a sua ação docente, bem como na organização e na dinamização da proposta pedagógica do curso. Concomitante a isso, pretendeu-se identificar qual percepção há em relaçáo ao espaço/tempo institucionalizado de formação e, se esse contribui para avanços e melhorias. Portanto, o estudo entrelaça as manifestaçóes dos entrevistados com os pressupostos teóricos, buscando analisar as concepçóes manifestadas e as implicaçôes nas práticas pedagógicas dos professores-formadores. Apesar de ensinar e aprender serem conceitos distintos, estabelecem relaçáo entre si, pois o ensinar só tem sentido como ação que tem por finalidade, ou intencionalidade, o aprender. E, sendo assim, a seguir, discutir-se-á a relaçáo que os professores-formadores estabeleceram entre esses dois conceitos.

\section{Ensinar: entendendo a complexidade a partir de concepçóes reveladas}

$\mathrm{O}$ processo de aprender e ensinar vem imbricado de complexas interaçóes em contextos multifacetados em que tensóes de todas as ordens se processam, e os sujeitos envolvidos manifestam diferentes comportamentos e necessidades. Há um emaranhado de interlocuçóes que se fazem necessárias para que o processo do ensinar e do aprender possa ocorrer e que nele se consolide a singularização de cada um. Marques (1996) destaca que a educação se faz num diálogo de saberes e 
não na simples troca de informaçóes, muito menos na mera aceitação acrítica das proposiçóes de outrem, ele afirma que a educação deve ser feita:

[...] na busca do entendimento compartilhado entre todos os que participem de mesma comunidade de vida, de trabalho, de uma comunidade discursiva de argumentação. Interlocução que se faça de saberes não apenas prévios, os saberes de cada um, sobretudo na participaçáo de cada um e de todos na reconstrução de que resultem novos saberes, os saberes de cada específica comunidade em cada diversa situação. Interlocuçấo que não é simples amálgama de saberes prévios, o trespasse de uns nos outros; mas é aprender contra o previamente aprendido, negação do que já se sabe na constituição de novo saber, de saberes outros (MARQUES, 1996, p. 14).

Assim, ao discutir a perspectiva do ensinar, busca-se em Irene, uma das entrevistadas, a manifestação sobre o que é ensinar, e percebe-se que ela aponta aspectos de sua complexidade e traz elementos que configuram a sua forma de pensar esse processo:

Irene: Ensinar é algo muito complexo, eu acho, porque primeiro para conseguir ensinar, eu pelo menos tenho que ter aprendido, e aprendido muito bem aquilo que eu quero ensinar, e não só ter aprendido o conteúdo, mas ter clareza de como isso vai ser feito. Então ensinar envolve uma série de momentos, eu acho, é pensar o conteúdo, é pensar como aquele conteúdo vai ser trabalhado, é pensar se o meu estudante tem condiçôes de entender esse conteúdo. Então ensinar... ensinar para mim é bastante complexo mesmo. Deixa eu pensar! O que mais... É isso, acho que o professor na verdade precisa ter muita clareza do que ele quer para que aí ele consiga ensinar, ele na verdade precisa ter uma organizaçáo muito grande do que ele pretende trabalhar.

É possível perceber, na fala da professora Irene, a preocupação com a complexidade do processo do ensinar, com a importância de pensar o outro nesse processo, ou seja, o aprendente. Irene defende que não basta o domínio do conteúdo específico da sua área do conhecimento, mas que há outros elementos necessários ao processo em discussão. Essa ideia já era expressa em Maldaner (2013, p. 62), que afirma que "[...] as crenças precisam ser refletidas e fundamentadas em novas bases de conhecimento das ciências da Pedagogia e dos conteúdos específicos, para que os professores possam modificar o ensino". Entende-se que os saberes docentes requeridos para a ação são mais amplos e não podem estar desvinculados da docência. Essa compreensão é importante para que possamos superar a ideia de que dominar o conhecimento disciplinar é suficiente para garantir a qualificação para o ensinar. Tardif (2014, p. 297) demonstra que há uma multiplicidade de conhecimentos/saberes que são mobilizados para a ação docente:

Os professores, em suas atividades profissionais se apoiam em diversas formas de saberes [...] o saber profissional dos professores não constitui um corpo homogêneo de conhecimentos; ele se serve, ao contrário, de uma ampla diversidade de conhecimentos e utiliza vários tipos de competências.

Portanto, a professora Irene demonstra compreender esses aspectos, especialmente reconhece a necessidade de outros saberes para além daqueles que 
dizem respeito ao conhecimento específico de sua área. Diferentemente da professora Irene, a professora Lise diz: "ensinar eu vejo como transmitir o conhecimento [...]". A manifestaçấo da professora Lise aponta para uma visão mais tradicional do ensinar. Talvez essa concepção advenha de sua formação, que pode ter sido construída com bases na racionalidade instrumental, a qual se fundamenta em uma concepção positivista de ciência e de formação profissional. A racionalidade técnica ou instrumental é "[...] uma concepção epistemológica da prática, herdada do positivismo, que prevaleceu ao longo de todo o século XX, servindo de referência para a educação e socialização dos profissionais em geral e dos docentes em particular" (PÉREZ GÓMES, 1995, p. 96), e sendo assim, influenciou/influencia muito a forma de pensar e agir de educadores. Desse modo, a compreensão expressa pela professora Lise pode ter sido constituído nessa perspectiva mais tradicional do processo de ensino e aprendizagem.

Entende-se que o ensinar é um constructo essencialmente humano para a socialização de saberes construído e sistematizado pela humanidade ao longo de toda a sua história. Há, nessa prática, a intenção de produzir aprendizagens e de que as novas geraçóes se apropriem dos saberes produzidos historicamente pela humanidade. Ao longo da história do processo educacional formal, diferentes propostas de como e o que ensinar foram sendo assumidas, com diferentes intencionalidades, por suas distintas concepçôes epistemológicas-educacionais.

Há algumas concepçóes sobre ensino, que permeiam as diferentes propostas educacionais, que foram, mesmo que de forma tangencial, manifestadas pelos entrevistados, especialmente no que diz respeito a processo de ensino e aprendizagem em Ciências. Pode-se identificar os modelos conhecidos como: transmissäo-recepção; descobrimento e construtivista.

$\mathrm{Na}$ manifestação da professora Emilie é possível identificar elementos que demonstram uma compreensão do processo de ensino-aprendizagem voltado para o modelo transmissão-recepção:

Emilie: Ensinar, eu entendo isso: a pessoa a quem você está transmitindo aquilo que você pensa que sabe, consiga absorver também. Mas assim oh! Não só engolir, porque muitas vezes nas minhas aulas, por exemplo, eu falo uma coisa errada de propósito, daí digo, ah! Mas, então tal coisa..., mas está errado aquilo, e eles ficam te olhando e não dizem que tu "errou", eles não dizem que tu "errou" porque tu é o professor, e eu digo: gente vocês concordam com o que eu disse? Sim prô (professora), a senhora é a professora. Eu digo, mas eu falei errado, vocês não estão prestando atenção em mim; eu falei de propósito para ver se alguém de vocês discute comigo. Então, aquele senso crítico sabe, é você fazer com que o aluno preste atençâo, e possa dizer não professora, não é assim. Aí, então, realmente, ele está prestando atenção, ele conseguiu absorver aquilo, e ele consegue discutir de igual para igual contigo. E eles parecem que não vem preparado para isso, então isso que eu acho que é o ensinar, é você conseguir fazer com que ele entenda, mas também tenha voz de dizer sim e não.

Assim, na manifestação da professora Emilie percebe-se elementos que caracterizam o modelo de transmissão-recepção, pois este concebe o conhecimento 
como verdadeiro e absoluto, por isso, a importância de ser transmitido ao outro. O fundamento epistemológico dessa compreensão é racionalista, e o psicológico é condutivista. Esse modo de pensar o ensinar, não considera como importante para o processo os conhecimentos prévios dos estudantes e nem o seu contexto de vivência. Há um forte pressuposto epistemológico que argumenta em favor da exterioridade dos conhecimentos em relaçáo ao educando e que para esse aprender, necessita, apenas, "prestar" muita atenção, como sinalizou a professora Emilie. Essa perspectiva é apresentada por Santos e Praia (1992, p. 13), ao afirmarem que a aprendizagem por transmissão

[...] radica, pois, no pressuposto epistemológico de que os conhecimentos existem fora de nós, e de que, para os aprender, é suficiente escutar - ouvir com atenção. Daí a sua grande preocupação em conseguir que o produto obtido (output) se situe tão próximo quanto possível do produto que entra (input).

Para Góes (1997, p. 12, grifo da autora), nesse processo de ensino, enfatizado por Emilie, é esperado que o professor transmita o que sabe e o sujeito aprendente receba os conhecimentos a que está sendo exposto, pois, no "[...] contexto pedagógico, o aluno pode ou não aprender tudo o que o professor transmite. Tais variaçóes entre os modos de funcionamento desses sujeitos acabam tendo um caráter quantitativo - o que se aprende corresponde a uma certa quantidade do conhecimento que se ensina”. No modelo de transmissão-recepção, o estudante tem um papel passivo e a centralidade da ação está no professor, o que demanda a forte crítica a esse processo. Como afirma Cachapuz (1999, p. 3):

Presume-se que o professor pode transmitir ideias pensadas por si próprio ou por outros (conteúdos) ao aluno que as armazena sequencialmente na sua mente (receptáculo). Ou seja, o professor 'dá a lição', os alunos armazenam e reproduzem a informação - uma visão claramente objectivista e instrumental do conhecimento e uma perspectiva behaviorista da aprendizagem.

Pierre, outro dos professores entrevistados manifesta uma compreensão que sinaliza para o modelo do descobrimento. O professor afirma que "o ensinar em ciências requer o desenvolvimento de aulas práticas como ponto importante, pois os alunos podem observar os fenômenos e, assim, compreender os conteúdos". $\mathrm{O}$ modelo do descobrimento tem sua centralidade na atividade experimental, com ênfase no fazer e não nos conceitos. Na manifestação do professor Pierre é possível perceber essa forte ênfase no experimental. Essa concepção parte da ideia de que, ao reproduzir o método científico no processo educacional, o estudante irá assimilar os conteúdos, constituindo-se como um investigador-pesquisador. Essa proposta enquadra-se na linha epistemológica empirista-indutivista-positivista, e na psicológica fortemente piagetiana, tendo na observação um princípio fundamental do processo.

Conforme Chalmers (1993, p. 23):

De acordo com o indutivista ingênuo, a ciência começa com a observação.

O observador científico deve ter órgáos sensitivos normais e inalterados e 
deve registrar fielmente o que puder ver, ouvir etc. em relação ao que está observando, e deve fazê-lo sem preconceitos. Afirmaçóes a respeito do estado do mundo, ou de alguma parte dele, podem ser justificadas ou estabelecidas como verdadeiras de maneira direta pelo uso dos sentidos do observador nãopreconceituoso. As afirmaçôes a que se chega (vou chamá-las de proposiçóes de observação) formam então a base a partir da qual as leis e teorias que constituem o conhecimento científico devem ser derivadas.

Francis Bacon, René Descartes e Galileu “[...] são considerados fundadores da ciência moderna, fundamentalmente por terem combatido o pensamento aristotélico, no qual a experiência tinha base na observação natural, mas também por terem contribuído para a estruturação do que ficou conhecido como método científico [...]" (GIORDAN, 1999, p. 45). Assim, ainda segundo Giordan (1999), essa concepçáa empirista-indutivista da Ciência, caracteriza o conhecimento científico como verdade provada ou descoberta, e que esse se origina pelo acúmulo de observaçôes cuidadosas de fenômenos, a partir da aplicação do método científico, podendo levar à construçáo de generalizaçôes cientificamente válidas, aspectos que se depreende da manifestaçáo do professor Pierre.

Portanto, o ensino por descoberta desvaloriza a criatividade do estudante e fundamenta uma visão de Ciência e conhecimento científico com verdades prontas e acabadas. No entanto, sabe-se que ao fazermos uma observação, selecionamos o que observar, ajustamos o foco, subsidiado pelas teorias (noções) pessoais e que estão relacionadas com o contexto no qual estamos inseridos. Sabe-se que essa concepção de ensinar, ainda, encontra-se fortemente presente no contexto educacional, especialmente nas aulas experimentais.

Schnetzler (2010) já nos alertava para a pouca eficácia desse modelo de ensino, chamando a atenção quanto a isso e sinalizando para a necessidade de considerar outros aspectos:

Os construtos teóricos da Ciência, produtos de elaboração e criação humana, e que permitem explicar, interpretar e prever fenômenos, náo provêm diretamente da observação e são, portanto, pouco prováveis de serem elaborados pelos alunos sozinhos. Ao contrário, estes precisam ser introduzidos, iniciados nestas ideias. E é o professor de Química, como representante dessa área de saber, que deve mediar tal conhecimento para os alunos por meio da linguagem (SCHNETZLER, 2010, p. 65).

No contraponto a esses dois modelos anteriores, podemos considerar o modelo construtivista, o qual considera o aprender como processo de reconstruçáo dos conhecimentos, que parte dos saberes prévios dos estudantes. Esse processo considera, ainda, a necessidade de negociação de significados para a evolução nos conceitos da Ciência, sendo esse mediado pelo outro. Tem-se como compreensão que o contexto social tem papel fundante no processo, sendo importante que seja considerado no momento da negociação de significados. O modelo construtivista baseia-se em teorias da aprendizagem como de Vigotsky e Ausubel. Para Góes (1997, p. 13, grifo da autora), esse processo no contexto pedagógico é “[...] uma visão que se apoia na concepçáo de um sujeito interativo (nem receptivo, nem apenas ativo), 
que elabora conhecimentos sobre objetos, em processos necessariamente mediados pelo outro e constituídos pela linguagem, pelo funcionamento dialógico”. O professor Max, outro entrevistado, em sua fala dá indícios que se aproximam de ideias que caracterizam essa concepção de ensino:

Max: Ensinar, então, tão simples e tão complexo. Então é o processo de transmitir conhecimento, mas não só uma transmissão vertical [...], mas o momento de mostrar ao estudante aquele caminho onde ele poderá chegar. São saberes importantes que quem está lá na frente, o professor, já tem, e no momento que ele consegue transmitir isso, ou construir junto com o estudante, acredito que é o momento que ele está ensinando [...].

Moreira e Sperling (2009), baseados nas teorias de Ausubel, afirmam ser fundamental, ou ainda mais, essencial, considerar o conhecimento prévio do estudante para o processo do ensinar-aprender, pois o ser humano aprende a partir do que já sabe e, sendo assim, o seu conhecimento prévio vai ter influência nesse processo de construção de conhecimentos. Thomas, um dos professores entrevistados, talvez tenha tentado dizer isso ao afirmar que para ensinar tem-se que "Tentar tornar mais próximo o conhecimento, tentar diminuir essas barreiras".

Assim, podemos afirmar que numa concepção que considera os conhecimentos prévios dos estudantes, o sentido e o lugar da experimentação, por exemplo, muda de perspectiva. Como já apontado no modelo por descoberta, a experimentação é pensada para comprovação de verdades, porém numa outra perspectiva, se volta para a compreensão de ciência como construçáo humana e, portanto, em que se admite o erro, a dúvida e o questionamento. Desse modo, conforme Giordan (1999), a experimentação necessita ser proposta em novas bases, as quais ampliam a compreensão sobre esse aspecto, permitindo avanços no que foi apontado pelo professor Pierre. Para o autor a experimentação deve ser percebida:

[...] como parte de um processo pleno de investigação [...] uma necessidade, reconhecida entre aqueles que pensam e fazem o ensino de ciências, pois a formaçáo do pensamento e das atitudes do sujeito deve se dar preferencialmente nos entremeios de atividades investigativas (GIORDAN, 1999, p. 44).

Devemos reconhecer o esforço dos professores-formadores entrevistados em caracterizar o que é ensinar, na tentativa de demonstrar suas melhores intencionalidades, mas essas estão, em parte, desprovidas de clareza teórica. Mesmo que a maioria tenha tido uma formação em cursos de licenciatura, muito provavelmente, a racionalidade em que essa formação se deu não possibilitou uma maior problematização acerca dessa temática. Dos entrevistados, três realizaram a graduação na década de 1980, três na década de 1990 e os outros seis nos anos 2000. Boa parte dos cursos de licenciatura tinha, e alguns ainda têm, como afirma Schön (1995), ancoragem na lógica da racionalidade técnica, segundo a qual, a prática docente dos currículos situava-se ao final dos cursos, desconsiderando o processo reflexivo sobre o fazer docente. Tem-se a compreensão que esse distanciamento entre teorias aprendidas desconexas de contextos reais não possibilita um avanço na compreensão, por parte do educador, de saberes requeridos para a docência. Ele 
tende a reproduzir de forma tácita um modo de ser e fazer vivenciado ao longo da sua formação, demonstrando dificuldade em superar a abordagem de cunho meramente positivista. Os entrevistados demonstram tendências por concepçóes de ensino e pressupostos epistemológicos que ainda requerem processos de problematizaçáo e ressignificação, para possibilitar novas percepções.

À medida que quem ensina não tem consciência de suas próprias concepçóes teórico-práticas e não há cientificidade nas bases epistemológico-educacionais que norteiam a prática desse docente, esse terá dificuldade em compreender os processos de ensinar e aprender, e todos os fatores que se relacionam a esses dois conceitos. As Ciências da Educação, a Psicologia e a Educação em Ciências/Química têm corroborado para elucidar como o ser humano aprende e que aspectos estáo imbricados nesse processo, que práticas e metodologias são requeridas para que o aprendente efetivamente aprenda. Entendemos que é necessário que os professoresformadores conheçam as teorias que dão sustentação às práticas do ensinar e, assim, possam identificar quais são as teorias mais adequadas para fundamentar um processo de aprender. Desse modo, podemos afirmar que urge o aumento de cientificidade nesse processo e, ao mesmo tempo, acreditamos que as açóes com vistas à formação continuada do professor-formador em espaços/tempos intrainstitucionais podem ajudar nessa construção.

Se entendemos que o ensinar objetiva a aprendizagem, se essa não ocorre, é possível afirmar que o professor ensinou? Apesar de todos os esforços demandados pelo professor, se não houve aprendizagem, talvez possamos dizer que ele não estava ensinando, mas havia ali uma tentativa de ensinar. Há, evidentemente, vários fatores a serem considerados, todas as intencionalidades, motivaçóes, condiçóes e recursos que estão sendo usados/disponibilizados para esse processo. Portanto, é possível pontuar que no processo de ensinar, que visa à aprendizagem do outro, podemos ter tentativas de ensinar, recheada de intencionalidades, para afirmar se essas resultaram ou não em aprendizagem necessitamos considerar diferentes elementos. Weissmann (1998, p. 32 - grifo nosso) afirma que "trata-se de reconhecer que todo o ato de ensino deve conter o propósito de transmitir um conhecimento, de tentar que alguém se aproprie de um conhecimento que inicialmente não possuía”.

Reconhecemos, portanto, que esse processo requer vários elementos, e apontamos, dentre outros, o planejamento como sendo um deles. Segundo Gauthier et al. (2013, p. 198) o planejamento "[...] consiste na disposiçáo de um conjunto de tarefas que visam, por exemplo, determinar os objetivos de aprendizagem, bem como priorizar e transformar os conteúdos em correspondência com os objetivos". Quando da sua manifestação a professora Irene apontou para essa direção: "[...] Então ensinar envolve uma série de momentos, eu acho, é pensar o conteúdo, é pensar como aquele conteúdo vai ser trabalhado, é pensar se o meu estudante tem condiçôes de entender esse conteúdo". Ao pontuar esses aspectos, ela estava descrevendo etapas/momentos de um planejamento voltado para a sua ação docente e, desse modo, sinalizando que ensinar é uma prática planejada decorrente de várias intencionalidades. 
Entáo se ensinar visa o aprender, se tomado esse pressuposto puramente, poderíamos estar sendo reducionistas e supervalorizando o ensinar. Ao mesmo tempo, nas relaçóes interpessoais, há outras nuances envolvidas para além dos processos meramente cognitivos, pois existem, por exemplo, também os aspectos socioafetivos que estáo ali imbricados. Mas isso daria outro enfoque, que não iremos discutir aqui. Feita essa ressalva vamos então assumir que o ensinar tem como intencionalidade o aprender. A professora Hildegarda em sua entrevista tangenciou essa compreensão ao firmar que:

Hildegarda: Ensinar a gente pode pensar em eu quero passar alguma coisa, eu tenho a intenção de ensinar ou, eu ensino, que são coisas diferentes. Eu tenho a intenção de passar para o aluno, enfim, alguns conhecimentos, então se ele vai aprender, isso é diferente de aluno para aluno, mas, a minha intenção é transmitir algum conhecimento para ele.

O que podemos depreender do que apresentam os entrevistados é que a aprendizagem como processo que resulta da açáo do ensinar, necessita ser mais bem conhecida e compreendida pelos educadores, especialmente, por atuarem em um curso de formação de futuros educadores. Entendemos que as concepçóes de ensinar e aprender estáo intimamente ligadas e, assim, necessitam de compreensão mais acurada pelos educadores.

\section{Aprender: como cada sujeito percebe o fenômeno e fornece indicativos para a análise}

A Escola, assim como a Universidade, conforme Marques (2006), é espaço privilegiado, de escolha social, para que o ensinar e o aprender ocorra. $\mathrm{O}$ autor afirma ainda:

[...] lugar, tempo e recursos destinados às aprendizagens em interação dialogal dos nelas interessados com Outro socialmente qualificado, para compartilharem do entendimento, da organização e da condução dos processos formais do aprender mediado pelo ensinar. E, quanto mais complexas, isto é, plural e diferençada, se apresente a sociedade, mais se exigem as aprendizagens sob a forma escolar, distinta das modalidades próprias de outros contextos sociais e âmbitos linguísticos (MARQUES, 2006, p. 87).

Consideramos que o aprender pode ser analisado a partir de três principais concepçôes epistemológicas: empirismo/indutivismo, apriorismo/inatismo e construtivismo/interacionismo, das quais decorrem diferentes concepçóes educacionais. Essas três concepçóes, em geral, determinam as açôes do educador e, portanto, contribuem para as escolhas metodológicas e às distintas formas de tratar o objeto do conhecimento. Ao mesmo tempo, direcionam o seu planejamento para o processo do ensinar. De forma consciente ou náo, o ensinar praticado pelo educador se filia a alguma concepçáo epistemológico-educacional que repercute num resultado de aprendizagem ou não, conforme Góes (1997).

Considerando-se o contexto pedagógico, o professor busca eleger certos sentidos, canalizando aí o esforço de elaboração, e transformar 
o funcionamento conceitual do aluno, na direção do conhecimento sistematizado. Também os pares são participantes das elaboraçóes conceituais do aluno. Dependendo da linha de ação pedagógica, os efeitos podem ou não corresponder aos conhecimentos pretendidos, podem gerar êxitos ou fracassos escolares (GÓES, 1997, p. 21).

$\mathrm{Na}$ concepção empirista/indutivista, entende-se que o conhecimento está fora do sujeito, situa-se no objeto. Para sua apreensão é necessário a realização de um número significativo de observaçóes/coleta de informaçôes para se estabelecer generalizações, teorias ou leis. Esse aspecto é o que fundamenta a concepção de ensino por transmissão, pois nessa compreensão o conhecimento está no objeto a ser conhecido, ele é obtido pela experiência dos sentidos, seja essa feita pela observação ou por o estudante "prestar" atenção, como pontuou a professora Emilie: "[...] fazer com que o aluno preste atenção [...]". A professora Dorothy, também, em sua manifestação sinaliza para essa concepção ao afirmar que aprender "[...] é justamente conseguir fazer, digamos assim, a introspecção daquilo que estava sendo o objeto daquela aula, ou daquele momento, daquele instante".

Para o empirista clássico, os verdadeiros fundamentos do conhecimento são acessíveis aos indivíduos através dos sentidos. Os empiristas supóem que os indivíduos possam estabelecer como verdadeiras algumas afirmaçóes confrontando o mundo através de seus sentidos. As afirmaçôes assim estabelecidas constituem os fundamentos sobre os quais é construído o conhecimento adicional por algum tipo de inferência indutiva (CHALMERS, 1993, p. 152-153).

No entanto, na concepção construtivista/interacionista tem-se o entendimento que o conhecimento se origina, se constrói, na interação do sujeito com a realidade, objeto do conhecimento. Assim, nesse processo modifica-se o meio enquanto esse modifica o próprio sujeito investigador. Nessa abordagem, admite-se que o sujeito adquire conhecimento de forma não passiva (em visão distinta da empirista) e nem pré-formada (diferentemente da visão apriorista/inatista). Portanto, aquele que aprende vai construindo formas próprias de ver e explicar o mundo, o contexto; seus modelos explicativos vão se tornando mais elaborados para compreender e interpretar a realidade, não sendo uma simples representaçáo dessa realidade. Para Góes (1997, p. 21), “[...] no pensamento vygotskiano, o conceito não é apenas representado pela palavra nem se reduz ao desenvolvimento de impressóes (pela percepção, pela memória). Forma-se por meio do uso da palavra, que náo é um rótulo aderido a uma ideia já estabelecida, a um conceito pronto". Desse modo, esse sujeito que se encontra em processo de aprendizagem, interage com o meio e, assim, vai construindo conhecimentos nesses processos de interaçáo, com uma organização lógica do pensamento. A entrevistada, professora Marie, aponta para essa compreensão de aprender:

Marie: Aprender? Então, é se apropriar de ideias, é saber racionalizar alguma coisa. Eu aprendi então, eu agora posso lidar com isso, pelo menos para mim sempre foi assim o aprendizado, agora que eu sei isso, eu consigo interagir com outras coisas que se ligam a esse fator. Eu posso pensar no assunto, para 
mim aí foi aprendido, agora eu sei pensar sobre aquilo, ir além, racionalizar, a partir daquela base, vamos dizer.

As afirmações da professora Marie remetem às perspectivas tratadas por Vigotsky (2008) relativas ao processo de internalização, em que aquilo que, inicialmente, é interpessoal se transforma em intrapessoal, na mediação do ensinar e do aprender, envolvendo as açôes do sujeito, as estratégias e os conhecimentos que ele já domina, conjuntamente com as açóes, as estratégias e os conhecimentos dos demais envolvidos no processo, e de todas as condiçóes sociais do contexto e das interaçóes que são viabilizadas. A professora Marie aponta, mesmo que não tâo convictamente para essa direção, porém pode-se dizer que, talvez, a professora necessita ainda pensar como colocar isso no processo de ensinar, pois ela descreve como ela percebe o seu aprender, náo fazendo alusão ao contexto dos seus educandos, especialmente ao não pontuar, no decorrer da sua fala, como ocorre ou como ela percebe esse processo de construção de aprendizagem nos estudantes, naqueles com os quais ela lida cotidianamente na sala de aula.

Pode-se ver que mesmo professores formados em três décadas distintas, apresentam significativas semelhanças ao pensar o contexto do ensinar e do aprender. Esse ciclo se reproduz mesmo que existam esforços para mudar. Hoje, as propostas curriculares dos cursos de licenciatura, a partir das demandas legais, careceriam derivar para uma concepção de uma racionalidade prática, distanciando-se da racionalidade meramente instrumental. Um aspecto que parece ser importante para se problematizar e que, certamente, contribui para que não ocorram significativas mudanças, é o grau de negligenciamento que o professor universitário tem quanto à sua formação continuada voltada, especialmente, para a docência, para as questóes do campo da educação, não aquelas concernentes à sua área de conhecimento específico. Maldaner (1999) alerta quanto à falta de comprometimento do educador dos cursos superiores sobre esse aspecto, afirmando que "Geralmente os professores universitários se comprometem pouco, muito aquém do necessário, com essa questão da formação dos professores e com a sua auto-formação pedagógica [...]" (MALDANER, 1999, p. 290), e o quanto esse "despreparo pedagógico dos professores universitários, também fruto de sua própria formação, afeta a formação em química de todos os profissionais que necessitam dessa área do conhecimento [...]" (MALDANER, 1999, p. 289).

Assim, percebe-se, a partir das manifestaçóes dos entrevistados, que as concepções de ensinar e aprender, construídas e constituídas ao longo dos processos educacionais, fundamentados em seus pressupostos epistemológicos, continuam a coexistir no contexto da educaçáo contemporânea, muitas vezes, mescladas em um mesmo sujeito, que não se vale de uma única percepção/concepção para a sua ação. Há aquelas concepçôes que sofrem uma crítica mais contundente pelo viés do olhar pedagógico, mas que ainda habitam fortemente o "chão" da sala de aula.

Como avançar? Uma possibilidade que entendemos como viável é pela formação continuada do professor em serviço, em diferentes contextos, mas especialmente em espaços/tempos intrainstitucionais. 


\section{A formaçáo contínua: uma construçáo com múltiplos significados}

Entendendo a importância da formaçáo continuada do educador, buscou-se investigar como esse profissional tem cuidado desse aspecto. Enfocou-se em duas possibilidades para delimitar o estudo. Assim, investigou-se a formação continuada do professor-formador pelo viés das suas leituras e participaçôes em eventos. Pensase essa formação na perspectiva de contribuir para o desenvolvimento pessoal e profissional do educador, capacitando-o para a sua ação pedagógica. Nas palavras de Nóvoa (1995):

A formaçáo deve estimular uma perspectiva crítico-reflexiva, que forneça aos professores os meios de um pensamento autónomo e que facilite as dinâmicas de autoformação participada. Estar em formação implica um investimento pessoal, um trabalho livre e criativo sobre os percursos e os projectos próprios, com vista à construção de uma identidade, que é também uma identidade profissional (NÓVOA, 1995, p. 25).

A seguir, a figura 1 apresenta os periódicos e os livros que os entrevistados mencionaram ter lido nos últimos três anos, versando sobre temáticas ligadas à educação. Alguns não mencionaram um periódico ou livro especificamente, fazendo uma menção genérica de leitura de artigos e livros.

Figura 1: Periódicos e livros mencionados pelos entrevistados, lidos nos últimos 3 anos, versando sobre educação

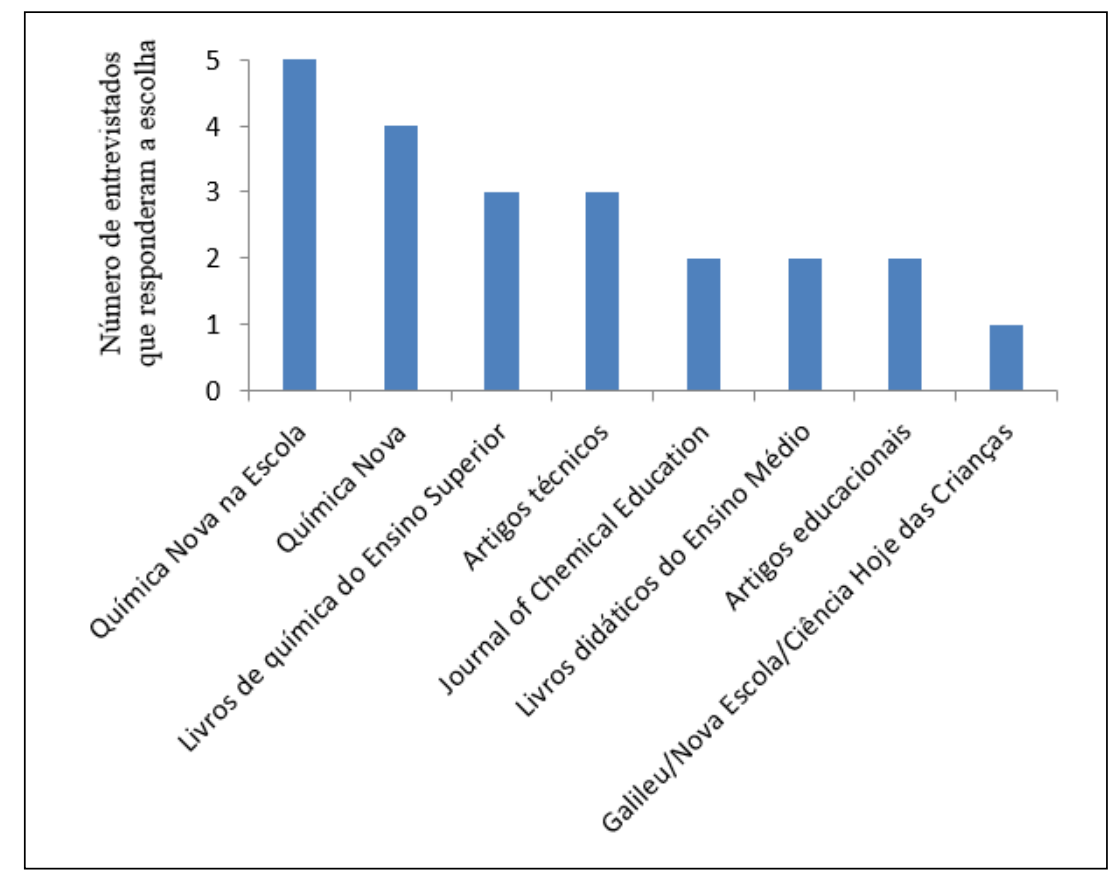

Fonte: Elaborado pelos autores 
Ao observar o que mencionaram os professores entrevistados, dentro da categoria periódicos, a Revista Química Nova na Escola foi a mais referida. Esse periódico traz artigos que buscam debater e refletir sobre o ensino e a aprendizagem de química. Entende-se que os artigos publicados nesse periódico podem se constituir em subsídio para a reflexão e o debate de temáticas relativas ao ser/fazer do professor, uma vez que a comunidade de educadores químicos tem publicado suas pesquisas sobre os processos do ensinar e do aprender nessa revista. Já o segundo mais mencionado, a Revista Quimica Nova é mais voltada para as áreas específicas da Química, tendo uma pequena parte destinada para artigos ligados à educação. O Journal of Chemical Education, considerado também uma publicação que corrobora os estudos e as compreensões de aspectos ligados à área, teve apenas duas citaçóes. No que se refere a livros, não houve nenhuma menção específica de algum relacionado à área de educação ou formação pedagógica.

Assim, conclui-se que, nesse aspecto, há um distanciamento do que se esperava, pois todos atuam em curso de graduação voltado para a formação docente e, portanto, as leituras concernentes à área de educação e formaçáo pedagógica deveriam ser muito mais significativas. Entendemos que aquilo que os professoresformadores leiam, em termos de periódicos e livros, poderão se constituir num material pedagógico muito interessante à medida que eles os utilizarem em suas aulas, nas reflexóes sobre as situaçóes vivenciadas nos processos da docência, problematizando e desmitificando os conceitos veiculados neles, do que se refere aos aspectos do cotidiano da sala de aula, entre outros tópicos, bem como, subsidiando a sua formação continuada de forma mais contundente.

Uma entrevistada mencionou a leitura da Revista Ciência Hoje das Crianças. Nessa revista a Ciência é mostrada às crianças de forma dinâmica, com mais atenção à correção conceitual. Esse tipo de revista se distingue de outras, assim como a Revista Ciência Hoje, segundo Oliveira (1993), porque é voltada para um público leitor com maior nível de escolaridade e, portanto, se preocupa em não banalizar os conceitos científicos. É importante, também, a escolha do tipo de periódico para fazermos nossas leituras, pois há aqueles que buscam ligar o universo científico ao cotidiano descuidando-se da cientificidade e da clareza conceitual. Eichler e Del Pino (2002) apontam uma das dificuldades da divulgação ampla do conhecimento químico:

[...] embora a Química seja uma das principais áreas produtoras de conhecimento, ela raramente é mencionada nos jornais e nas revistas dirigidas ao público leigo. Em relação às prioridades da mídia anteriormente esboçadas, tal diferença não é difícil de compreender. Grande parte da pesquisa em Química não pode ser facilmente relacionada com interesses humanos imediatos (EICHLER; DEL PINO, 2002, p. 24).

Entendemos que esse aspecto não deve se caracterizar como um entrave para os professores-formadores, uma vez que são graduados e pós-graduados na área de Química, bem como deveriam ter compreensôes sobre as temáticas educacionais mais amplas, já que atuam em curso de formação de futuros educadores. 
Também foi solicitado aos entrevistados que fizessem uma apreciação sobre o valor dessas leituras para a sua formação continuada e para a sua ação como docente. Veja-se o que afirma Marie, ao ponderar quanto elas ajudam:

Mari: Ajudam a refletir, porque eu vou fazer aquilo, ou então, porque que eu dei aquilo se na verdade náo vai fazer muito efeito. Enfim, ou até na questão assim, de sistematizar, como que você vai abordar, ou até o que você vai abordar, porque às vezes tu não 'tem' ideia de quanto tu podes ir num assunto.

Podemos perceber que, para a professora Mari, as leituras cumprem papel importante para o seu planejamento, para o direcionamento das atividades e situaçôes que irá propor em sala de aula. Uma fala bem significativa é a apresentada pela professora Emmy, quando ela afirma:

Emmy: Muito, porque, por exemplo, quando eu comecei a trabalhar como professora, eu acho que eu vim naquela coisa de mestrado, quando tu "tem" que apresentar alguma coisa tu montas um power point e tu apresenta, é isso que a gente aprende no mestrado. Aí quando eu tive que ser professora, eu ainda tinha aquela ideia [...] então isso abriu minha visão, porque tinha várias técnicas de trabalhar, que eu só sabia aquelas que eu tinha... Eu era vista como aluna, aquelas que eu lembrava eu ainda não tinha coragem de aplicar, e depois que eu li o livro me abriu um pouco mais.

O que é possível depreender com a afirmação da professora Emmy é que ela ainda, em seu processo inicial de atuação docente, não se percebia como educadora, pois estava muito presente a sua percepção do ser educador que vivenciou como estudante. O processo de interação com os pares, no contexto da formação continuada desenvolvida no NEQ, e as leituras que passou a realizar ajudou a avançar nessa percepção e, como ela expressa em seus argumentos, contribuiu para a construçáo de sua identidade como professora.

Entendemos que um outro aspecto que pode contribuir para esse processo de construção da identidade profissional e, de modo geral ajudar o professor a pensar a sua ação como educador, é a formação em cursos, seminários, encontros, palestras e outras atividades (eventos) que tenham como objetivo problematizar as perspectivas teórico-epistemológicas-pedagógicas do educador sobre os processos do ensinar e aprender.

A seguir, a figura 2 traz os dados referente aos eventos que os professoresformadores mencionaram terem participado, nos últimos três anos, ligados à educação, voltados para o aperfeiçoamento e para a reflexão da ação pedagógica do professor. 
Figura 2: Participação em eventos nos últimos 3 anos, envolvendo a temática educação

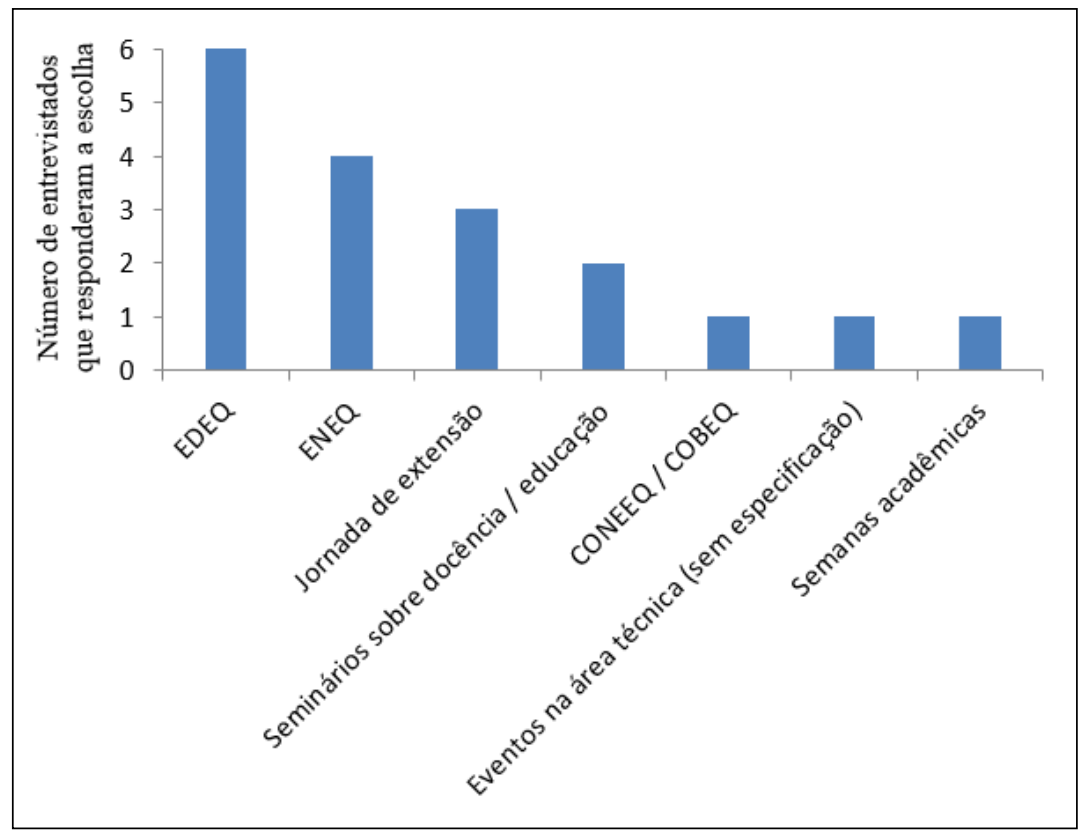

Fonte: Elaborado pelos autores.

A participaçáo em eventos por parte dos professores entrevistados também se considera insipiente. Não foi expresso um número significativo e claro de eventos que possam potencialmente sinalizar contribuiçáo para o aperfeiçoamento e a reflexão sobre a docência e todos os aspectos dela decorrentes, pelos entrevistados. Considere-se ainda, que os que responderam participar do ENEQ (Encontro Nacional de Ensino de Química) e EDEQ (Encontro de Debates sobre o Ensino de Química) são os mesmos indivíduos entrevistados. Há eventos mencionados que apresentam pouca contribuição para a reflexão pedagógica, contribuindo de forma mais incisiva para o aperfeiçoamento do conhecimento técnico, específico da área da disciplina do educador, o que também é necessário, mas não é objeto de análise neste trabalho. Entre esses eventos, tem-se o Congresso Nacional dos Estudantes de Engenharia Química (CONEEQ) e o Congresso Brasileiro de Engenharia Química (COBEQ).

Assim, entendemos que, diante da necessidade de avanços na melhoria da educação, na busca por uma melhor formação do futuro educador, precisamos considerar o que é proposto por Maldaner (1999, p. 289):

[...] se pense um professor em constante atualizaçáo, capaz de interagir positivamente com os seus alunos, problematizar as suas vivências e convertêlas em material de reflexão com base nas construçóes das ciências e outras formas culturais e, assim, contribuir para a transformação e recriação social e cultural do meio. 
Sobre os eventos, os entrevistados também fizeram uma apreciação desses para a sua formação continuada. O professor Max afirmou que "[...] ajuda na questão de ressignificar alguns conceitos, talvez, que a gente já tenha e, também, melhorar enfim, a prática. É preciso muitas vezes ver coisas diferentes, ou até para ver se está no caminho certo, muitas vezes, a gente percebe isso também".

Pierre, outro professor entrevistado, apontou "[...] que todos eles são ricos, porque daí, de uma forma, vem ao encontro dos objetivos que é a atualização, que é a formação e a troca de experiências, troca de saberes, a gente acaba sempre agregando novos conhecimentos quando participa de congressos ou seminários desse gênero". Mas o que podemos observar em ambas as falas dos professores-formadores é uma superficialidade, sem que adentre em questôes mais específicas para a qualificação da sua profissionalização docente. As demais falas dos entrevistados seguem a mesma direção.

Isso nos remete a pensar o que vem proposto por García (1995):

Isto significa que o modelo de ensino e, consequentemente, o modelo de professor assumido pelo sistema educativo e pela sociedade tem de estar presente, impregnando as actividades de formaçáo de professores, a todos os níveis. Este princípio implica, também, a necessidade de existir uma forte interconexão entre o currículo de formação inicial de professores e o currículo da formação permanente de professores (GARCÍA, 1995, p. 55).

Isso requer, portanto, uma mudança de paradigma, capaz de romper com os ditames construídos a partir do modelo da racionalidade técnica e estabelecer possibilidades rumando a uma nova racionalidade de formaçáo docente, a da prática. Desse modo, o professor-formador necessita de uma formação para a docência, em que as concepçóes epistemológicas-educacionais da/na ação docente sejam problematizadas. Por muitas vezes esse aspecto não ter sido construído no decorrer da formação inicial, defendemos que se tenha espaços/tempos para que isso ocorrer num processo de formação continuada em serviço. Concordamos com Schnetzler (2002) e Cachapuz et al. (2001) ao apontarem que os professores necessitam assumir a responsabilidade, por intermédio do diálogo e interação com os seus pares, pela construção da sua identidade profissional, desenvolvida "[...] pela formação de um novo tipo de profissional acadêmico - o/a pesquisador/a em ensino de Ciências/Química" (SCHNETZLER, 2002, p. 14), que, desse modo, possibilite a superação da racionalidade que ainda persiste na formação para a docência.

\section{Espaço/Tempo de formaçáo intrainstitucional: possibilidade de superaçáo de fragilidades}

$\mathrm{Na}$ tentativa de minimizar parte da fragilidade na formação dos professoresformadores investigados, no ano de 2003, a instituição de ensino a qual eles estáo vinculados, formalizou a existência do NEQ (Núcleo de Educação Química), um espaço/tempo constituído para a discussão e a elaboração coletiva, incluindo uma determinada carga horária no contrato de trabalho para que todos os professores da área de Química participem. Com reunióes quinzenais, esse tem sido o fórum em 
que ocorrem trocas de experiências na busca por uma reflexáo permanente do fazer pedagógico dos professores de Química. Nesse fórum, são preparados projetos, realizadas avaliações, elaborados e discutidos coletivamente materiais pedagógicos como apostilas e livros, analisados artigos e livros.

Como o grupo é dinâmico, pois alguns educadores são professores permanentes do quadro da área de Química da universidade e outros são contratados temporários, dos dez entrevistados, na ocasião da entrevista, um participava há um semestre, um há dois semestres, duas no decorrer de três semestres, um professor e uma professora há cinco anos e os demais desde a sua constituição. São múltiplas as demandas e situaçôes que passam pelo NEQ e, muitas vezes, as questóes pedagógicas e análises educacionais são tangenciadas, pois o grupo tem uma autogestão.

As instituiçóes de ensino superior, responsáveis na grande maioria pela formação dos educadores que atuam na educação básica, em geral, não têm espaços/ tempos institucionalizados para a formação continuada em serviço dos professoresformadores. Entendemos que "Institucionalizar esse debate já é, por si só, um primeiro passo. Esse debate não pode ser deixado à mercê da possível vontade de alguns professores interessados. Ele é imprescindível à vida de qualquer curso de graduação e, por isso, obrigação de todos os professores" (LAUXEN et al., 2016, p. 203). Assim, a proposição do NEQ foi e está sendo fundamental para a qualificação docente e tem contribuído substancialmente para a reflexão dos professores, como avaliam os entrevistados ao falarem sobre a importância desse espaço/tempo. Veja-se o que diz a entrevistada professora Dorothy:

Dorothy: [...] com o NEQ eu melhorei bastante o meu planejamento, a parte de avaliação, também, que contribuiu bastante, a minha reflexão sobre essa parte de avaliação, que é uma coisa que eu não tinha antes, não fazia, muito profundo assim, só mais o básico, e também, a parte de fazer coisas diferentes, testar coisas diferentes, e poder comparar os resultados com quem também faz.

Tardif e Lessard (2013) apontam que a produção de "saberes docentes" de forma consciente é favorecida pela criação de espaços/tempos de discussão, em que o professor possa refletir sobre os limites dos conhecimentos acadêmicos na constituição do saber docente, da mesma forma, a sua experiência profissional torna-se elemento importante nessa construção. Zeichner (1995) corrobora essa ideia, afirmando que os professores produzem em suas práticas uma gama de conhecimentos que, conjuntamente com suas experiências, deverá ser ponto de partida de qualquer mudança que se deseja realizar. Assim, se no conjunto dos professores-formadores tornar-se possível criar espaços/tempos para a formaçáo continuada em serviço, dentro da instituição, certamente, haverá avanços, pois irão ocorrer trocas, no confronto das diferentes concepçóes, pela busca de consensos.

O NEQ congrega sujeitos com diferentes concepçôes sobre ensinar e aprender, como revelado na pesquisa, esses profissionais têm tempos diferentes de atuação docente, vêm de lugares distintos de formação e atuam em disciplinas diversas, porém no diálogo que se faz entre os pares, avanços vão sendo produzidos, como 
também foi revelado pelos professores-formadores pesquisados. Assim, o NEQ se constitui como espaço/tempo de formação, no diálogo e confronto de saberes entre os pares, tendo a preocupação com a educaçáo, o ensino, as aprendizagens e os avanços pedagógicos requeridos para a melhoria da qualidade educativa.

\section{Consideraçóes finais}

As análises e reflexóes produzidas a partir dos elementos presentes na pesquisa, trazidos do que foi apresentado pelos entrevistados apontam que os professores filiam-se a modelos epistemológicos de ensino e aprendizagem, que ora pontuam mais para o empirismo e a transmissão-recepçáo, ora já se apresentam mais associados às concepçôes cognitivistas e ao processo de mediação do ensinar e aprender.

Podemos apontar que as concepçóes e crenças do professor-formador, mesmo daqueles das disciplinas específicas da área de Química, contribuem para a formação de concepçôes do ser educador no futuro professor, sendo assim, é importante reconhecer e refletir como essas influenciam as suas práticas na ação e nesse contexto, como apontam as tomadas de decisóes em sala de aula. As concepçóes se interligam com as práticas, pois elas as fundamentam. Dessa forma, quanto mais teorias científicas estiverem dando base às concepçóes do professor-formador, especialmente no que tange ao campo pedagógico, mais reflexóes ele poderá produzir na e sobre a sua prática. Portanto, a formação continuada do professor-formador deve ser uma preocupação das instituiçóes, oportunizando espaços/tempos intrainstitucionais para esse processo, ao mesmo tempo em que incentivam a participação em espaços de diálogo interinstitucionais, eventos e outras modalidades de aperfeiçoamento, como, por exemplo, a leitura de periódicos e livros do campo da didática das ciências.

Há uma formação ambiental, construída ao longo do processo de escolarização, a qual exerce uma força muito grande na concepção do ser docente, e quando pensamos nos professores-formadores dos cursos universitários, reconhecese que muitos deles não tiveram essa formação para a docência, a não ser a formação tácita. Então, para que um professor-formador possa, adequadamente, contribuir na formação de um futuro docente é necessário que domine muito mais do que os conhecimentos relativos à sua disciplina a ser ministrada, requer um conjunto de aspectos que vão para além do domínio dos conteúdos conceituais, necessita também, dos conteúdos atitudinais e dos procedimentais como partes do processo de ensino e aprendizagem. Para que possa formar esse cidadão, profissional comprometido e engajado, o professor-formador deverá ter uma visão mais alargada do contexto, abarcando aspectos sociais, éticos e políticos do meio no qual está inserido.

Quando se discute a formação do futuro docente e se questiona a qualidade dessa formação, vários aspectos são usados para justificar. Há aquela velha forma de se "empurrar" a culpa para o que veio antes, ou seja, se os estudantes não estáo sendo mais bem qualificados é por que estáo chegando à universidade com deficiências 
que os impedem de acompanhar o processo. Outras vezes, as justificativas recaem sobre os currículos, que estão inadequados e exigem cada vez menos dos estudantes. Raras são as vezes em que surge a dúvida de se o problema não está na formação dos docentes que atuam nesses cursos (MALDANER, 1999; GONÇALVES; GONÇALVES, 2011).

Desse modo, entende-se que as instituições de ensino superior, responsáveis pela formação dos futuros educadores da educação básica têm assumido, ao longo do tempo, a difícil tarefa de romper com a formaçáo baseada na racionalidade técnica, especialmente em vista do questionamento que esse modelo sofreu/sofre nos últimos tempos. Contudo, ao mesmo tempo, se defronta com professores-formadores que tiveram um processo formativo alicerçado nesse mesmo modelo, sendo muitos em cursos sem formação pedagógica (bacharelados), ou seja, a docência, nesse contexto, se faz pela formação ambiental/tácita.

Entende-se que a prática docente se constitui em uma atividade complexa, e que muitos dos professores que atuam nos cursos de licenciatura náo compreendem e náo reconhecem essa complexidade. Como consequência dessa ausência de consciência do que efetivamente envolve o processo de ensino e aprendizagem, esse professor não consegue estabelecer um processo de reflexão capaz de romper com a formaçáo ambiental e tácita que constitui sua visão do ser educador, perpetuando uma percepção simplista e reducionista do ser e fazer docente, o que contribui para que não ocorra mudanças e rupturas.

Talvez, então, tornar o professor pesquisador de sua prática de forma permanente e um sujeito reflexivo (ZANON et al., 2016) e, como apontado por Lauxen (2002), garantir que esse processo de reflexão não seja um exercício meramente introspectivo, mas algo que venha a ser feito no coletivo dos educadores, permitindo a construção de saberes advindos de uma prática refletida, possa ser um caminho para que avanços ocorram. Nesse caso, entendemos que espaços/tempos como o Núcleo de Educação Química (NEQ) podem ser a alternativa para que isso venha ocorrer de forma qualificada e permanente. Assim, defende-se a necessidade da constituição de espaços/tempos intrainstitucionais para que os professoresformadores possam, de forma coletiva com seus pares, refletir sobre sua prática docente e, dessa forma, contribuir para a melhoria na qualidade educativa, e formar professores mais bem preparados para a escola básica.

\section{Referências}

BOGDAN, R.; BIKLEN, S. K. Investigaçáo qualitativa em educaçáo: uma introdução à teoria e aos métodos. Porto: Porto Editora, 2010.

CACHAPUZ, A. F. Epistemologia e ensino das ciências no pós mudança conceptual: uma análise de um percurso de pesquisa. Associaçáo Brasileira de Pesquisa em Educaçáo em Ciências (Org.), Anais do II Encontro Nacional de Pesquisa em Educação em Ciências. Valinhos: ABRAPEC, 1999. 
CACHAPUZ, A. F.; PRAIA, J.; GIL-PÉREZ, D.; CARRASCOSA, J.; MARTÍNEZTERRADES, I. A emergência da didáctica das ciências como campo específico de conhecimento. Revista Portuguesa de Educaçáo, v. 14, n. 1, p. 155-195, 2001.

CHALMERS, A. F. O que é ciência, afinal?. São Paulo: Brasiliense, 1993.

CURY, C. R. J. A qualidade da educação brasileira como direito. Educaçáo \& Sociedade, v. 35, n. 129, Campinas-SP, p. 1053-1066, 2014.

DEMO, P. Educar pela pesquisa. 9. ed. Campinas: Autores Associados, 2011.

EICHLER, M.; DEL PINO, J. C. Popularização da Ciência e Mídia Digital no Ensino de Química. Química Nova na Escola. São Paulo: SBQ. N. 15, p. 24-27, mai. 2002.

GALIAZZI, M. do C. Educar pela Pesquisa: ambiente de formação de professores de ciências. Ijuí: Unijuí, 2011.

GAUTHIER, C.; MARTINEAU, S.; DESBIENS, J. F.; MALO, A.; SIMARD, D. Por uma teoria da pedagogia: pesquisas contemporâneas sobre o saber docente. 3. Ed. Ijuí: Unijuí, 2013.

GARCÍA, C. M. A formação de professores: centro de atenção e pedra-de-toque. In: NÓVOA, A. (Coord). Os professores e a sua formaçáo. Lisboa: Dom Quixote, 1995. p. 53-76.

GIORDAN, M. O papel da experimentação no ensino de ciências. Química Nova na Escola. n. 10, nov. p. 43-49, 1999.

GOÉS, M. C. R. As relações intersubjetivas na construção de conhecimentos. In: GÓES, M. C. R. et al. A significaçáo nos espaços educacionais: interação social e subjetivação. Campinas, SP: Papirus, 1997. p. 11-28. (Coleção Magistério: Formação e trabalho pedagógico)

GONÇALVES, T. O.; GONÇALVES, T. V. O. Reflexões sobre uma prática docente situada: buscando novas perspectivas para a formação de professores. In: GERALDI, C. M. G.; FIORENTINI, D.; PEREIRA, E. M. de A. (Org.). Cartografia do trabalho docente: professor(a)-pesquisador(a). 2. Ed. Campinas, SP: Mercado de Letras, 2011. p. 105-134.

\section{LAUXEN, A. A. (Des)consideraçáo das questóes ambientais no ensino formal de} ciências: o caso das escolas de Ibirubá. Ijuí: Unijuí, 2002.

LAUXEN, A. A.; MISTURA, C. M.; PRADO, E. A.; ORTIZ, J. C. A formação inicial em Química no contexto de uma universidade comunitária. In: ECHEVERRÍA, A. R.; ZANON, L. B. (Org.). Formação superior em química no Brasil: práticas e fundamentos curriculares. 2. Ed. Ijuí, Ed. Unijuí, 2016. p. 187-208. 
LIBÂNEO, J. C.; PIMENTA, S. G. Formação de profissionais da educação: visão crítica e perspectiva de mudança. In: Educaçáo \& Sociedade, ano XX, n. 68, Campinas, p. 239277, Dez, 1999.

LIBÂNEO, J. C. Formação de professores e didática para desenvolvimento humano. In: Educaçáo \& Realidade, vol.40, n.2, Porto Alegre, p. 629-650abr./jun, 2015.

LIMA, P. G.; BARRETO, E. M. G.; LIMA, R. R. Formação docente: uma reflexão necessária. In: Educere et Educare. Vol. 2 n. 4, Cascavel, p. 91-101, jul/dez, 2007.

LÜDKE, M.; ANDRÉ, M. E. D. A. de. Pesquisa em educaçáo: abordagens qualitativas. São Paulo: EPU, 2013.

MACHADO, N. J. Qualidade da educação: cinco lembretes e uma lembrança. Estudos Avançados. v. 21, n. 61, São Paulo, p. 277-294, set/dez 2007.

MALDANER, O. A. A pesquisa como perspectiva de formação continuada do professor de química. Química Nova. São Paulo: SBQ. V. 22, n. 2, p. 289-292, mar./abr. 1999.

. A formaçáo inicial e continuada de professores de química professor/ pesquisador. 4. Ed. Ijuí: Unijuí, 2013.

MARQUES, M. O. Educaçáo / interlocuçáo, aprendizagem / reconstruçáo de saberes. Ijuí: Unijuí, 1996.

. A aprendizagem na mediaçáo social do aprendido e da docência. 3. Ed. Ijuí: Unijuí, 2006.

MORAES, R.; GALIAZZI, M. do C. Análise textual discursiva. 3. ed. Ijuí: Unijuí, 2016.

MOREIRA, M. A.; SPERLING, C. S. Mapas conceptuales y aprendizaje significativo: ¿una correlación necesaria? Experiências em Ensino de Ciências, V4 n. 3, p. 91-100, 2009.

NÓVOA, A. Formação de professores e profissão docente. In. __. (Coord). Os professores e a sua formaçáo. 2. Ed. Lisboa: Dom Quixote, 1995. p. 15-33.

OLIVEIRA, R. J. de. As revistas de divulgação científica e a transmissão do conhecimento: uma abordagem sobre o ensino informal de ciências. Contexto \& Educação. Ijuí: Unijuí, ano 8, n. 32, p. 81-94, out/dez 1993.

PÉREZ GÓMEZ, A. O pensamento prático do professor: a formação do professor como profissional reflexivo. In: NÓVOA, António (Coord). Os professores e a sua formaçáo. 2. Ed. Lisboa: Dom Quixote, 1995. p. 93-114.

SANTOS, E. M. dos; PRAIA, J. F. Percurso de mudança na didáctica das ciências. Sua fundamentação epistemológica. In: CACHAPUZ, A. F. (Coord.), Ensino das Ciências e 
Formaçáo de Professores, n. 1, Projecto MUTARE, Aveiro: Universidade de Aveiro, p. 11-34, 1992.

SCHNETZLER, R. P. A pesquisa em ensino de Química no Brasil: conquistas e perspectivas. Química Nova, vol. 15, supl. 1, p. 14-24, 2002.

Apontamentos sobre a história do ensino de Química no Brasil. In: SANTOS, W. L. P. dos S.; MALDANER, O. A. (Org.). Ensino de Química em foco. Ijuí: Unijuí, 2010. p. $51-75$.

SCHÖN, D. A. Formar professores como profissionais reflexivos. In: NÓVOA, António (Coord). Os professores e a sua formaçáo. 2. Ed. Lisboa: Dom Quixote, 1995. p. 77-91.

TARDIF, M.; LESSARD, C. O trabalho docente: elementos para uma teoria da docência como profissão de interaçóes humanas. 8. ed. Petrópolis, RJ: Vozes, 2013.

TARDIF, M. Saberes docentes e formaçáo profissional. 17. Ed. Petrópolis, RJ: Vozes, 2014.

VARGAS, M. de L. F; PEIXOTO, M. do C. de L. A formação em Pedagogia na Faculdade de Educação da UFMG: um olhar a partir das percepçóes de professores e egressos. In: Educar em Revista, v. 35, n. 76, Curitiba, p. 279-304, jul/ago, 2019,

VIGOTSKY, L. S. Pensamento e linguagem. 4. Ed. São Paulo: Martins Fontes, 2008.

WEISSMANN, H. O que ensinam os professores quando ensinam Ciências Naturais e o que dizem querer ensinar. In: WEISSMANN, Hilda (Org.). Didática das ciências naturais: contribuiçóes e reflexóes. Porto Alegre: ArtMed, 1998. p. 31-55

YIN, R. K. Estudo de caso: planejamento e métodos. 2. ed. Porto Alegre. Editora: Bookmam, 2001.

ZANON, L. B.; FRISON, M. D.; MALDANER, O. A. Articulação entre desenvolvimento curricular e formação inicial de professores de Química. In: ECHEVERRÍA, A. R.; ZANON, L. B. (Org.). Formaçáo superior em química no Brasil: práticas e fundamentos curriculares. 2. Ed. Ijuí: Ed. Unijuí, 2016. p. 208-231.

ZEICHNER, K. M. Los profesores como profesionales reflexivos y la democratización de la reforma escolar. In: FUNDACIÓN PAIDEIA. Volver a pensar la educación (v. II). Prácticas y discursos educativos (Congreso Internacional de Didáctica). Madrid: Morata, 1995. 